\title{
Effect of TCSC on Line Voltage Stability Indices under Single Line Outage Condition
}

\author{
Merlyn Mathew ${ }^{1}$, D. Suresh Babu ${ }^{2}$, P.S.Venkataramu ${ }^{3}$, M.S.Nagaraj ${ }^{4}$ \\ M. Tech Scholar, Department of Electrical \& Electronics Engineering, LNCTE, Bhopal, India ${ }^{1}$ \\ Asst Professor, Dept of Electrical \& Electronics Engg, Sree Vidyanikethan Engineering College, Tirupati, AP, India ${ }^{2}$ \\ Director-IQAC, Reva University, Bangalore, Karnataka, India ${ }^{3}$ \\ Professor\& Head, Department of Electrical \& Electronics Engineering, BIET, Davangere, Karnataka, India ${ }^{4}$
}

\begin{abstract}
Voltage stability issues have attracted the interest of power system researchers worldwide. It is important to maintain the system stability, or else it would lead to voltage collapse and consequently complete blackout of the system. In this paper the voltage stability indices, Fast Voltage Stability Index (FVSI) and Voltage Reactive Power Index $\left(\mathrm{VQI}_{\mathrm{Line}}\right)$ are used to determine the stability of a system. These indices are used to identify the most critical line and bus of the system. Under single line outage condition, effect of placing a TCSC in the system on FVSI \& VQI $\mathrm{L}_{\text {Line }}$ has been observed. An IEEE 6 bus system has been considered for simulation purpose.
\end{abstract}

Keywords: TCSC, FVSI, VQI, Enhancement Index.

\section{INTRODUCTION}

Voltage stability is one of the most important issues addressed by the power system engineers and planners today. Because of the increase in load demand the modern power systems are forced to carry increasingly more power over long distances. One of the major problems that may associate with such a stressed system is the voltage instability or collapse. Voltage stability is the ability of a power system to maintain steady voltages at all buses in the system after being subjected to a disturbance from a given initial operating condition [1].

A review of the literature on methods or techniques to study voltage collapse reveals that various analytical tools based on different concepts have been proposed to predict voltage collapse. Several methods have been used for static voltage stability analysis such as the P-V and Q-V curves, modal analysis, etc. [2]. Line voltage stability indices (LVSI) provide important information about the proximity of the system to voltage collapse and are also used to identify the critical line of the system [3]. These indices provide reliable information about the closeness of the system towards voltage instability and the weakest bus and line in the system. An effective solution to improve the voltage profile and voltage stability of the power system is to place an appropriate Flexible AC transmission system (FACTS) controller in the power system. FACTS controller use reliable high speed thyristor based control elements and have the capability of improving power transmission capacity and voltage profile, enhancing power system stability, minimizing transmission losses etc.

\section{FACTS DEVICES}

The benefits of using Flexible AC Transmission system (FACTS) controllers for enhancing power system stability are well known.
The use of these controllers gives grid planners and operators a greater flexibility regarding the type of control actions that can be taken at any given time [4].The utmost requirement of power system is to meet the demand, which varies continuously. That is, the amount of power delivered by the power companies must be equal to that of consumer's need. But events such as faults, tripping of lines etc. causes an imbalance in the reactive power which needs to be compensated. Thus to compensate for the reactive power requirement of the system FACT devices are installed at suitable location. FACT devices offer a number of merits such as fast control characteristics, reactive power compensation increase in dynamic stability, enhances the loading capability of lines and maintains system security.

The basic function of FACT devices is to control the power flow actively and effectively. In other words, it can transfer power flow from one line to another within its capability.

\section{A. TCSC}

Thyristor controlled series compensator (TCSC) device is a series compensator which governs the power flow by compensating the reactance of the transmission line. Both capacitive and inductive reactance compensations are possible by proper selection of capacitor and inductor values of the TCSC device.

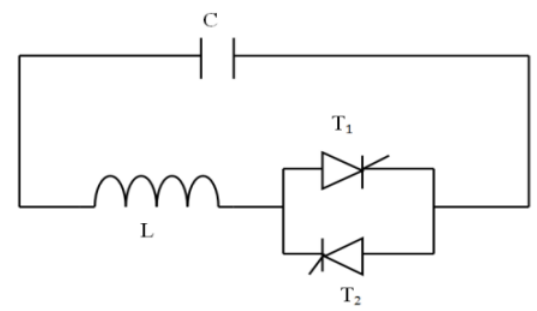

Fig1. A schematic diagram of TCSC 
Fig. 1 shows a TCSC which consists of a series compensating capacitor (C) shunted by a thyristor controlled reactor (TCR) [5].

1) Inductive Mode:

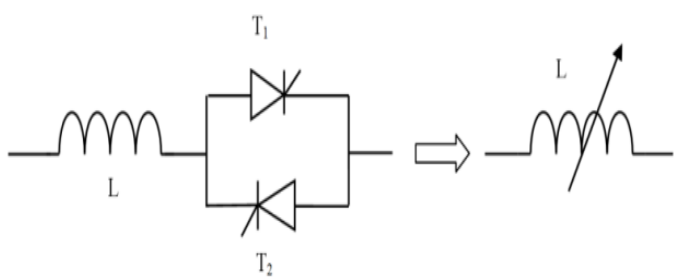

Fig2. TCSC Inductive Mode

TCR is a variable inductive reactor $X_{L}(\alpha)$, tuned at firing angle, as shown in Fig. 2. The variation of $X_{L}$ with respect to alpha $(\alpha)$ can be given as:

$$
\begin{aligned}
\mathrm{X}_{\mathrm{L}}(\alpha)=\mathrm{X}_{\mathrm{L}} & \frac{\pi}{\pi-2 \alpha-\sin 2 \alpha} \\
\mathrm{X}_{\mathrm{C}} & =\frac{1}{2 \pi \mathrm{fC}} \ldots \ldots \ldots(2)
\end{aligned}
$$

For the variation of $(\alpha)$ from 0 to $90, X_{L}(\alpha)$ varies from actual reactance $\left(\mathrm{X}_{\mathrm{L}}\right)$ to infinity.

2) Capacitive Mode:
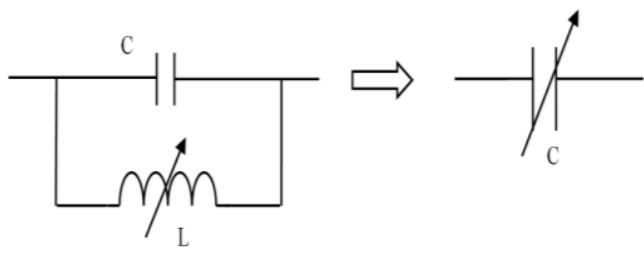

Fig3. TCSC Capacitive Mode

The controlled reactor is connected across the series capacitor, so that the variable capacitive reactance, as shown in Fig. 3, is possible across the TCSC which modifies the transmission line impedance. Effective TCSC reactance $X_{\text {TCSC }}$ with respect to alpha $(\alpha)$ can be given as:

$$
\begin{aligned}
\mathrm{X}_{\mathrm{TCSC}}(\alpha)=-\mathrm{X}_{\mathrm{C}} & +\mathrm{C}_{1}(2(\pi-\alpha)+\sin (2(\pi-\alpha))) \\
& -\mathrm{C}_{2} \cos ^{2}(\pi-\alpha)(\omega \tan (\omega(\pi-\alpha)) \\
& -\tan (\pi-\alpha)) \ldots .(3)
\end{aligned}
$$

Where,

$$
\begin{aligned}
\mathrm{C}_{1} & =\frac{\mathrm{X}_{\mathrm{C}}+\mathrm{X}_{\mathrm{LC}}}{\pi} \ldots(4) \\
\mathrm{C}_{2} & =4 \frac{\mathrm{X}_{\mathrm{LC}}^{2}}{\mathrm{X}_{\mathrm{L}} \pi} \ldots \ldots(5) \\
\mathrm{X}_{\mathrm{LC}} & =\frac{\mathrm{X}_{\mathrm{L}} \mathrm{X}_{\mathrm{C}}}{\mathrm{X}_{\mathrm{C}}-\mathrm{X}_{\mathrm{L}}} \ldots(6) \\
\omega & =\sqrt{\frac{\mathrm{X}_{\mathrm{C}}}{\mathrm{X}_{\mathrm{L}}}} \ldots \ldots(7)
\end{aligned}
$$

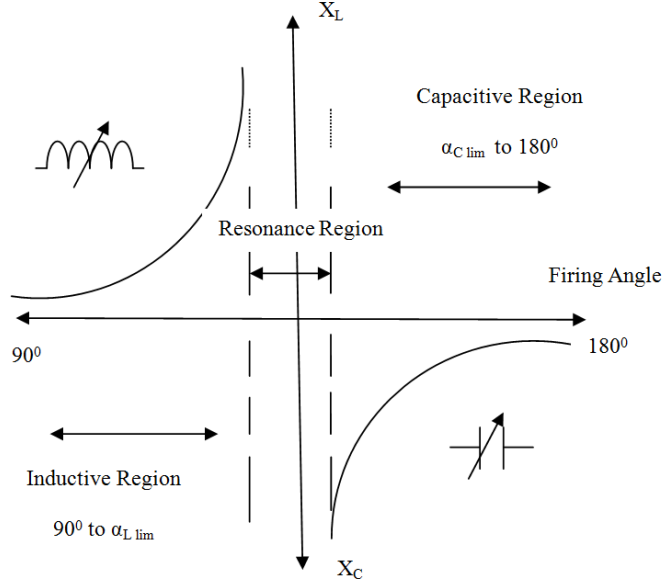

Fig4. TCSC reactance Vs firing angle characteristics curve

\section{LINE VOLTAGE STABILITY INDICES}

The condition of voltage stability in a power system can be known using voltage stability indices. These indices either reveal the critical bus of a power system or the stability of each line connected between two buses in an interconnected network and evaluates the voltage stability margins of the system. The indices are discussed below:

\section{A. Fast Voltage Stability Index FVSI}

The line stability index FVSI proposed by I.Musirin et al. [6] is based on the concept of power flow through a single line. For a typical transmission line, the stability index is calculated as:

Let us consider a simple two-bus power system model:

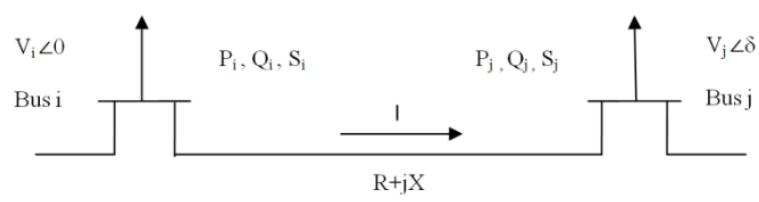

Fig 5 .Two bus system for FVSI formulation

$$
\begin{gathered}
I=\frac{V_{i} \angle 0-V_{j} \angle \delta}{R+j X} \\
I_{j}=\frac{P_{j}-j Q_{j}}{V_{j} \angle-\delta} \ldots
\end{gathered}
$$

Equating (8) \& (9)

$$
V_{i} V_{j}<-\delta-V_{j}^{2}=(R+j X)\left(P_{j}-j Q_{j}\right) \ldots
$$

Hence a quadratic equation of $V_{j}$ can be formed:

$$
\begin{aligned}
V_{j}^{2}+V_{i} V_{j}\left(\frac{R \sin \delta}{X}\right. & -\cos \delta)+Q_{j}\left(\frac{R^{2}+X^{2}}{X}\right) \\
& =0 \ldots \ldots(11)
\end{aligned}
$$

For real values to exist for $V_{j}$ there must be real roots of the equation

$$
V_{i}^{2}\left(\frac{R \sin \delta-X \cos \delta}{X}\right)^{2}-4 Q_{j}\left(\frac{R^{2}+X^{2}}{X}\right) \geq 0
$$


The expression has real roots only if

$$
\frac{4 Z^{2} Q_{j} X}{V_{i}^{2}(R \sin \delta+X \cos \delta)^{2}} \leq 1.0 \ldots .
$$

By assuming that $\delta \approx 0, \approx 0, X \cos \delta \approx X$, we can define the fast voltage stability index for line $i-j$

Where

$$
F V S I_{i j}=\frac{4 Z^{2} Q_{j}}{V_{i}^{2} X} \ldots \ldots
$$

$Z$ = line impedence

$X=$ line reactance

$Q_{j}=$ reactive power flow at the receiving end

$V_{i}=$ sending end voltage

When the FVSI of a line approaches unity it means that the line is approaching its stability limits. The FVSI of all the lines must be lower than 1 to assure the stability of the power system. The line that gives index value closest to 1 will be the most critical line of the bus and may lead to the whole system instability. The calculated FVSI can thus be used to determine the weakest bus of the system.

B. Voltage Reactive Power Index $\mathrm{VQI}_{\text {Line }}$

F.A. Althowibi [7] proposed an index $\mathrm{VQI}_{\text {line }}$ through power flow equations. The line with index value closer to 1 is considered as the line which is more prone to instability and can cause the entire system to collapse.

Consider a two bus single line system as illustrated in Fig.6, which can be extended to an n-line power system.

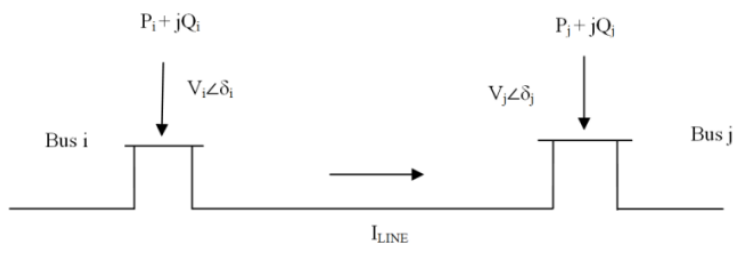

Fig6. A two bus system

Where:

$V_{i}, V_{j}=$ sending and receiving voltages at system buses

$\delta_{i}, \delta_{j}=$ sending and receiving voltages angle at system bus $\mathrm{i}$ and $\mathrm{j}$

$P_{i}, P_{j}=$ sending and receiving end real power

$Q_{i}, Q_{j}=$ sending and receiving reactive power

$Y_{i j}=(G+j B)$ line admittance between bus $\mathrm{k}$ and $\mathrm{m}$

$\theta=$ line admittance angle

$r+j x=$ line impedance between bus $\mathrm{i}$ and $\mathrm{j}$

When bus $\mathrm{i}$ is taken as a reference bus, the line current $I_{\text {line }}$ is calculated by:

$$
I_{\text {line }}=\left(V_{i}-V_{j}\right) Y_{i j}
$$

The current $I_{\text {line }}$ can also be determined by using the receiving end power at bus $\mathrm{j}$, given as,

$$
I_{\text {line }}=\left(\frac{s_{j}}{V_{j}}\right)^{*}=\frac{\left(P_{j}-j Q_{j}\right)}{V_{j}<-\delta_{j}}
$$

Rearranging equation (15) \& (16) yields:

$$
P_{j}-j Q_{j}=\left|V_{j} V_{i} Y_{i j}\right| \angle\left(\theta-\delta_{j}\right)-\left|V_{j}\right|^{2} \cdot\left|Y_{i j}\right| \angle \theta \ldots
$$

The real and imaginary parts can be separated from equation (17) as:

$$
\begin{gathered}
\operatorname{Re}: P_{j}= \\
\left|V_{j} V_{i} Y_{i j}\right| \angle\left(\theta-\delta_{j}\right)-\left|V_{j}\right|^{2} \cdot\left|Y_{i j}\right| \cdot \cos (\theta) \ldots \ldots \\
\operatorname{Im:} Q_{j}= \\
\left|V_{j} V_{i} Y_{i j}\right| \angle\left(\theta-\delta_{j}\right)-\left|V_{j}\right|^{2} \cdot\left|Y_{i j}\right| \cdot \sin (\theta) \ldots \ldots
\end{gathered}
$$

Substituting equation (18) into equation (17) to establish a relationship between $V_{i}$ and $Q_{j}$ yields:

$$
V Q I_{\text {Line }}=\frac{4 Q_{j} X_{i j}}{V_{i}^{2}} \ldots \ldots
$$

$\mathrm{Q}_{\mathrm{j}}=$ reactive power flow at the receiving end $\mathrm{V}_{\mathrm{i}}=$ sending end voltage

$$
\begin{aligned}
& \left|V_{j} V_{i} Y_{i j}\right| \angle\left(\theta-\delta_{j}\right)-\left|V_{j}\right|^{2} \cdot\left|Y_{i j}\right| \cdot \cos (\theta)-j Q_{j} \\
& =\left|V_{j} V_{i} Y_{i j}\right| \angle\left(\theta-\delta_{j}\right) \\
& -\left|V_{j}\right|^{2} \cdot\left|Y_{i j}\right| \angle \theta \text {.. } \\
& \left|V_{j}\right|^{2}-\left|V_{j} V_{i}\right| \frac{\left(\sin \left(\theta-\delta_{j}\right)\right)}{(\sin (\theta))}+\frac{Q_{j}}{\left|Y_{i j}\right|(\sin (\theta))}=0 \ldots
\end{aligned}
$$

Since $\delta_{j}$ is very small, it is assumed to be zero seeking equation simplification, then the whole term of $\frac{\left(\sin \left(\theta-\delta_{j}\right)\right)}{(\sin (\theta))}$ is eliminated and yields,

$$
\left|V_{j}\right|^{2}-\left|V_{j} i\right|+\frac{Q_{j}}{\left|Y_{i j}\right|(\sin (\theta))}=0 \ldots .
$$

Since, $B_{i j}=Y_{i j} \sin (\theta)$, the new equation can be rewritten as,

$$
\left|V_{j}\right|^{2}-\left|V_{j} V_{i}\right|+\frac{Q_{j}}{\left|B_{i j}\right|}=0 \ldots .
$$

The roots of $V_{j}$ is expressed as:

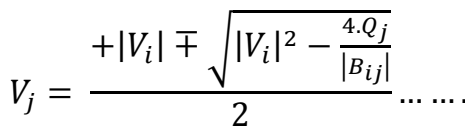

Eq. (25) gives one distinct real root or two equal roots of $V_{j}$ if discriminate $\left(\Delta=b^{2}-4 a c\right)$ is zero. The discriminated roots of $V_{j}$ can be expressed as

$$
\left\{\begin{array}{c}
\left|V_{i}\right|^{2}-\frac{4 \cdot Q_{j}}{\left|B_{i j}\right|} \leq 0 \\
\frac{4 \cdot Q_{j}}{\left|B_{i j}\right| \cdot\left|V_{i}\right|^{2}} \leq 1
\end{array}\right.
$$

$V_{j}$ varies from zero to one indicating the real root limitation and can be used as the voltage stability limits. The voltage real roots must be greater than zero and lower than one, otherwise the voltage stability is to be compromised; this proves that the developed equation determines voltage stability at each line and predicts system voltage collapse, and is thus named as voltage reactive power index of line, $\mathrm{VQI}_{\text {Line }}$, and given as :

$$
\mathrm{VQI}_{\text {Line }}=\frac{4 . \mathrm{Q}_{\mathrm{j}}}{\left|\mathrm{B}_{\mathrm{ij}}\right| \cdot\left|\mathrm{V}_{\mathrm{i}}\right|^{2}} \leq 1.0 \ldots .
$$

Thus, if the value of $\mathrm{VQI}_{\text {Line }}$ approaches unity, the voltage stability reaches its stability limits. Voltage instability occurs when $\mathrm{VQI}_{\text {Line }}$ is beyond unity. $\mathrm{VQI}_{\text {Line }}$ determines how far the power system is from instability or collapse point. 


\section{PROPOSED ALGORITHM}

- Read the system data

- Run the load flow without line outage contingency and use the results as base case

- Connect N-1 line outage contingency between any two buses and obtain load flow results

- Calculate the values of FVSI and $\mathrm{VQI}_{\mathrm{Line}}$ from the equations (14) \& (27)

- Rank the weakest / most critical line from the base case and line outage contingency condition having highest value of FVSI and VQI $\mathrm{Line}_{\text {Lin }}$

- Connect TCSC at the most critical line i.e. between load buses (neglecting the generator buses).

- Obtain the results with TCSC connected in the line for each inductive and capacitive mode of $10 \%$ to $50 \%$ compensation.

- Compare the calculated values of indices with and without TCSC

- Calculate the \% enhancement of the indices as given in section 5 .

\section{ENHANCEMENT INDEX}

The enhancement index can be calculated which determines the percentage enhancement observed in the transmission line after placement of TCSC. The enhancement index can be defined as:

$$
\% \text { Enhancement Index }=\frac{\text { VSI }_{\text {Base }}-\text { VSI }_{\mathrm{TCSC}}}{\mathrm{VSI}_{\mathrm{TCSC}}} \times 100
$$

Where VSI $_{\text {Base }}$ is Voltage Stability Index without TCSC $\mathrm{VSI}_{\mathrm{TCSC}}$ is voltage stability index with TCSC

VSI $_{\text {Base }}$ is any index i.e. FVSI or VQI Line

\section{CASE STUDY \& RESULTS}

To demonstrate the effectiveness of methodology an IEEE 6 bus system is considered. This system consists of 11 transmission lines, bus 1 is considered as slack bus, bus 2 $\& 3$ are the generator buses, and buses $4,5 \& 6$ as the load buses respectively. The computation was done in the two cases.

\section{A. FVSI}

1) FVSI enhancement using TCSC in inductive mode of compensation:

By the computation of indices it was found that the FVSI value is maximum for line 4-5, neglecting the generator buses, hence a TCSC was placed on line 4-5 and enhanced values of indices were calculated. From table 1 it is observed that for line 2- 4 \& 3-6 negative enhancement is taking place i.e. the values of indices with TCSC are higher than without TCSC. For line 3-5 a positive enhancement has occurred during $10 \%$ to $20 \%$ compensation, for $30 \%$ compensation no change in enhancement, \& from $40 \%$ to $50 \%$ compensation a positive enhancement took place. For line 1-5, continuous increment in enhancement index was observed from $10 \%$ to $50 \%$ compensation as $43 \%$ to $147 \%$ respectively.
2) FVSI enhancement using TCSC in capacitive mode of compensation:

For line 2-4 a positive enhancement took place from $10 \%$ to $50 \%$ compensation and a continuous increment in enhancement index was observed from $78 \%$ to $325 \%$ respectively.

B. $\mathrm{VQI}_{\text {Line }}$

1) VQILine enhancement using TCSC in inductive mode of compensation:

By the computation of indices it was found that the FVSI value is maximum for line 5-6, neglecting the generator buses, hence a TCSC was placed on line 5-6 and enhanced values of indices were calculated. From table 2 lines 1-5, 2-5, 3-5, 4-5 2-6, 3-6 showed negative enhancements and a continuous increment in enhancement index can be observed from $10 \%$ to $50 \%$ compensation.

2) $\mathrm{VQI}_{\text {Line }}$ enhancement using TCSC in capacitive mode of compensation:

From table 2 it can be observed that lines showed positive enhancement and a continuous increment in the values of enhancement index can be observed from $10 \%$ to $50 \%$ compensation.

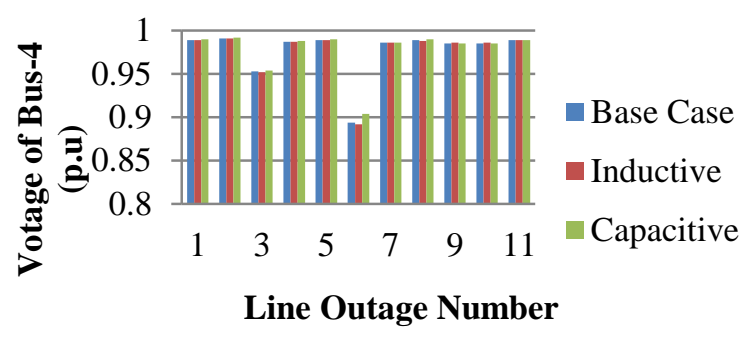

Fig7. Voltage Profile Bus 5

Fig. 7 shows Voltage Profile of bus-5 for base case, inductive and capacitive modes. From the above graph it can be observed that the voltage values are enhanced in the inductive $\&$ capacitive modes. The maximum variation in voltage at bus 4 is observed under 3-6 outage condition.

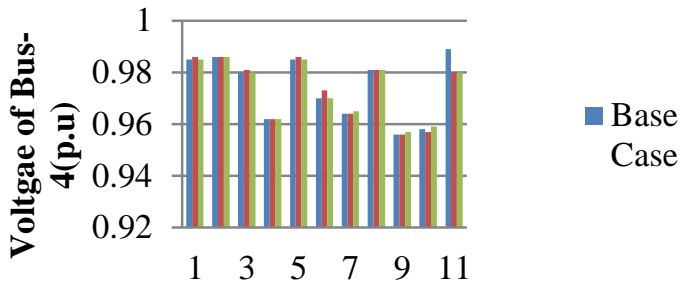

Line Outage Number

Fig8. Voltage Profile of Bus 4

The voltages Profile for bus - 4 for base case, inductive and capacitive modes are as shown above. It can be observed that the values of voltages are enhanced considerably in the capacitive mode. The maximum variation in voltage at bus 4 is observed under 2-4 outage condition. 
Table 1.FVSI \% Enhancement

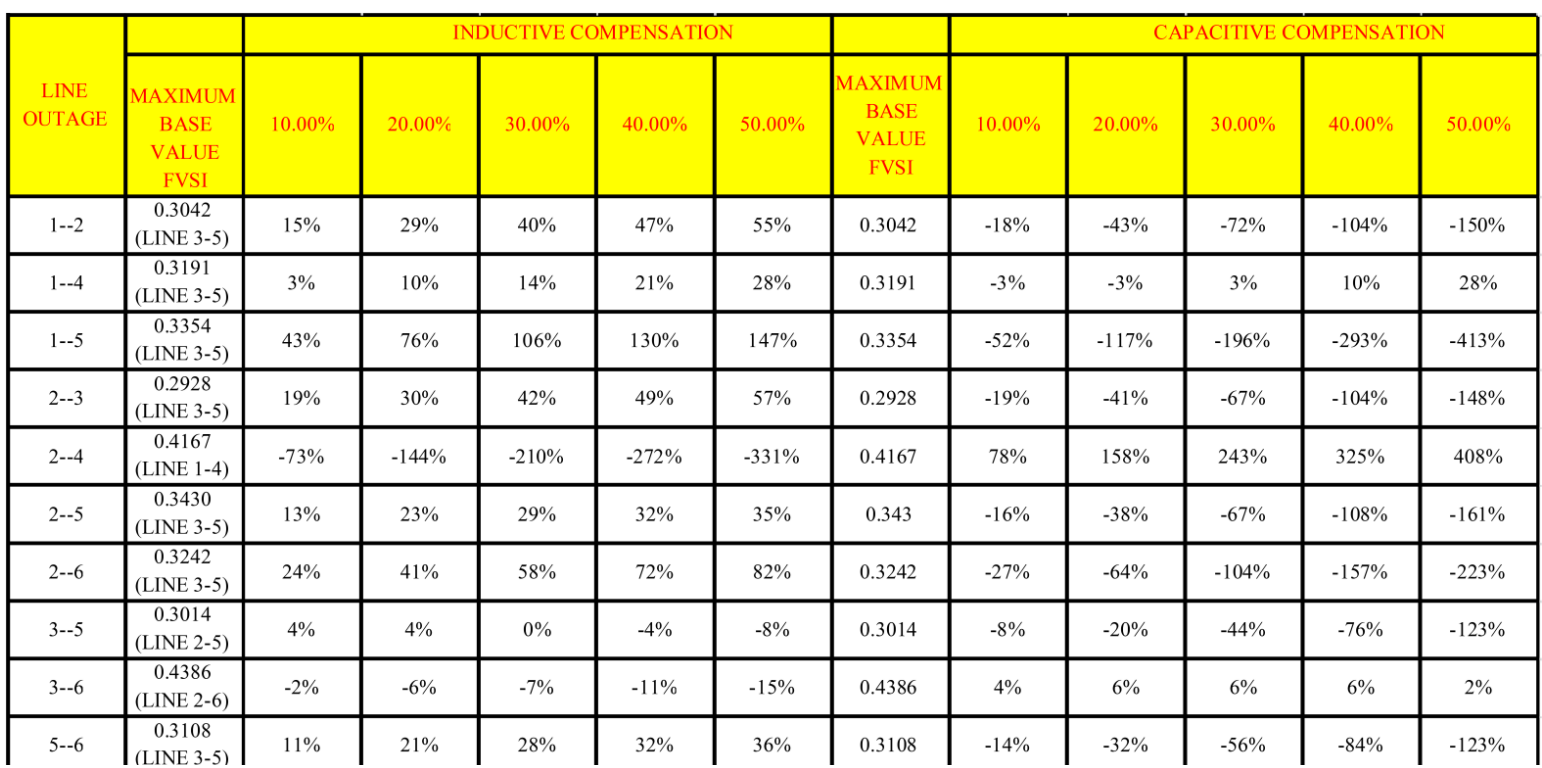

Table 2.VQI \% Enhancement

\begin{tabular}{|c|c|c|c|c|c|c|c|c|c|c|c|c|}
\hline \multirow[b]{2}{*}{$\begin{array}{c}\text { LINE } \\
\text { OUTAGE }\end{array}$} & & \multicolumn{5}{|c|}{ INDUCTIVE COMPENSATION } & & \multicolumn{5}{|c|}{ CAPACITIVE COMPENSATION } \\
\hline & $\begin{array}{c}\text { MAXIMUM } \\
\text { BASE } \\
\text { VALUE VQ }\end{array}$ & $10.00 \%$ & $20.00 \%$ & $30.00 \%$ & $40.00 \%$ & $50.00 \%$ & $\begin{array}{l}\text { MAXIMUM } \\
\text { BASE } \\
\text { VALUE VQ }\end{array}$ & $10.00 \%$ & $20.00 \%$ & $30.00 \%$ & $40.00 \%$ & $50.00 \%$ \\
\hline $1--2$ & $\begin{array}{c}0.2508 \\
\text { (LINE 3-5) } \\
\end{array}$ & $-58 \%$ & $-111 \%$ & $-157 \%$ & $-199 \%$ & $-237 \%$ & 0.2508 & $66 \%$ & $143 \%$ & $234 \%$ & $337 \%$ & $458 \%$ \\
\hline $1--5$ & $\begin{array}{c}0.2765 \\
\text { (LINE 3-5) }\end{array}$ & $-56 \%$ & $-110 \%$ & $-158 \%$ & $-203 \%$ & $-244 \%$ & 0.2765 & $59 \%$ & $126 \%$ & $198 \%$ & $270 \%$ & $347 \%$ \\
\hline $2--3$ & $\begin{array}{c}0.2414 \\
\text { (LINE 3-5) }\end{array}$ & $-45 \%$ & $-86 \%$ & $-126 \%$ & $-159 \%$ & $-192 \%$ & 0.2414 & $53 \%$ & $114 \%$ & $184 \%$ & $259 \%$ & $346 \%$ \\
\hline $2--4$ & $\begin{array}{c}0.3922 \\
\text { (LINE 1-4) }\end{array}$ & $-13 \%$ & $-24 \%$ & $-33 \%$ & $-44 \%$ & $-52 \%$ & 0.3922 & $13 \%$ & $30 \%$ & $46 \%$ & $65 \%$ & $88 \%$ \\
\hline $3--5$ & $\begin{array}{c}0.2713 \\
\text { (LINE 2-5) }\end{array}$ & $-80 \%$ & $-154 \%$ & $-220 \%$ & $-281 \%$ & $-337 \%$ & 0.2713 & $89 \%$ & $188 \%$ & $297 \%$ & $422 \%$ & $555 \%$ \\
\hline $3--6$ & $\begin{array}{c}0.3907 \\
\text { (LINE 2-6) }\end{array}$ & $-52 \%$ & $-103 \%$ & $-154 \%$ & $-206 \%$ & $-253 \%$ & 0.3907 & $50 \%$ & $98 \%$ & $137 \%$ & $172 \%$ & $191 \%$ \\
\hline $4--5$ & $\begin{array}{c}0.2348 \\
\text { (LINE 3-5) }\end{array}$ & $-50 \%$ & $-96 \%$ & $-1.34 \%$ & $-171 \%$ & $-205 \%$ & 0.2348 & $58 \%$ & $121 \%$ & $193 \%$ & $270 \%$ & $361 \%$ \\
\hline
\end{tabular}

\section{CONCLUSION}

Line Voltage Stability Indices gives an indication about the system stability. The value of the indices helps in identifying the most critical transmission line in the system. A TCSC is installed at the most severe line and as a result enhanced values of line voltage stability indices i.e. FVSI and VQI are obtained. Thus it is observed that the severity of the line is reduced. Installation of TCSC at the most suitable location also improves the voltage profile of the buses.

\section{ACKNOWLEDGEMENT}

The Authors are grateful to the management of Gyan Ganga Institute of Management Bhopal and the management of Bapuji Institute of Engineering and Technology for all support during the research work.

\section{REFERENCES}

[1] P.Kundur "Power System Stability and Control" McGraw-Hill, New York, 1994

[2] Claudia Reis, F.P. Maciel Barbosa et. al. "A Comparison of Voltage Stability indices" IEEE MELECON, pp. 1007-1010, May 16-19 2006, Benalmadena (Malaga), Spain.

[3] C. Reis and F.P. Maciel Barbosa, "Line Indices for Voltage Stability Assessment" IEEE Bucharest Power Tech Conference, pp.1-6, June 28- 2 July 2009 Bucharest.

[4] Alberto D. Del Rosso,Victor M. Dona "A Study of TCSC controller Design System Stability Improvement” IEEE Transactions On Power Systems Vol. 18 pp. 1487-1496 17 Nov 2003.

[5] S. Meikandasivam, Rajesh Kumar Nema, Shailendra Kumar Jain "Selection of TCSC Parameters Inductive \& Capacitive" IEEE IICPE Conference pp. 15, 28-30 Jan 2011, New Delhi

[6] Ismail Musirin and TitikKhawa Abdul Rahman "Novel Fast Voltage Stability Index (FVSI) for Voltage Stability Analysis in Power Transmission System" IEEE Student Conference on Research and Development Proceedings, pp. 265-268, 2002

[7] F.A. Althowibi, M.W. Mustafa "Line Voltage Stability Calculations in Power Systems" IEEE International conference on power and energy, pp. 396-401, Nov 29-Dec 12010 Kaula Lumpur, Malaysia.

[8] MatPower4.0 